1918. It will be formed by the combination of the Annals of Obhthalmology, the Ophthalmic Record, Obhthalmology, the Ophthalmic Year Book, and Ophthalmic Literature. The omission of the names of certain periodicals will be noted, but there are reasons for believing that at least one of them will enter the combination. The newcomer will be owned by a company, the shares in which will be largely held by ophthalmic surgeons, and in order to prevent the stock from becoming of speculative value, it has been arranged that it shall always remain in the hands of ophthalmologists. It is believed that "the new journal will probably start with the largest list of subscribers of any ophthalmic journal published in the world," and it is hoped that "it will offer its contributors the best presentation of their papers, both as to paper, presswork, proof reading, and illustrations that it is possible to secure in America" (Ophthalmic Literature, July, 1917).

\title{
The Children of Blinded Soldiers
}

That indefatigable worker in the interests of the blind, Sir Arthur Pearson, has issued an appeal for providing a fund whereby every child born to a blinded soldier after his disablement shall be allowed 5s. a week until the age of sixteen. It is estimated that the total sum required for this purpose may amount to $£ 250,000$.

\section{The Eyesight of Colliery Officials}

The Home Secretary has drawn the attention of medical practitioners to a particular section of the Coal Mines Act, 1911, which requires that certified firemen, examiners, or deputies must obtain every five years a new certificate that their eyesight is adequate to enable them to conduct proper tests for inflammable gas, and that their hearing enables them to perform their duties efficiently. Such certificate may be obtained from an authority approved by the Secretary of State or from a medical practitioner. The new certificate must be made out in the prescribed form (Mines and Quarries Form, No. 73), and can only be granted after applying certain specified tests.

\section{War Nephritis}

In Sundell and Nankivell's article in the Lancet of September 15,1917 , the eye changes in war nephritis (35 consecutive cases) are thus reported by Capt. R: Graham Brown :-

"The fundus was normal in 29, while in 6 slight blurring of a 
portion of the disc margin or papillœedema was present. All these patients had facial odema. The retinal change and the facial œedema appeared to clear up at the same time. No case was under observation at a sufficiently late stage for chronic changes to be manifest. Transient blindness occurred in two cases as one of several uraemic symptoms. Difficulty in reading was complained of by a few patients early in the disease, and some of these had slight blurring of the disc; but it is doubtful whether this disability could not be explained by general causes."

\section{ABSTRACTS}

\section{I.-WRITING IN ORDINARY CHARACTERS FOR THE BLIND}

\section{Cantonnet, A. (Paris).-Writing for the blind in ordinary characters. (Ecriture d'aveugles en caractères usuels.) La Clin. Ophtal., March, I9I7.}

The reviewer, who, it may be remembered, had the pleasure of translating into English the late Emil Javal's "Entre Aveugles," has been very greatly interested in this article by Cantonnet, in which is described an embossed writing, after the fashion of Braille, but in such characters that the writing may be read by eye as well as by touch without any previous knowledge of embossed writing. For blinded soldiers, who, for the most part, come from the less educated classes, and for their friends, this is an enormous advantage. It is true, the author says, that Braille has a number of advantages over this writing of his; it is universally known, it is briefer, it is quicker, it has been applied to stenography and to music, but, on the other hand, it cannot be read by everybody. The two procedures are not mutually exclusive; they are complementary to one another. "The blind person who knows Braille and wishes to study, or who corresponds with those who know Braille, will employ Braille. The less educated individual, or the man who does not know Braille, will use my method of writing."

The main features of this method are extremely simple, although perhaps not so easy to describe without the author's illustrations of the frame required and of the letters and numerals. Essentially, it amounts to this, that each capital letter of the ordinary alphabet can be represented by the use of a certain number of the nine points in a square of which each side is composed of three points. In illustration, 